\title{
Review of Problems of Adolescent Sexual Behavior and the Role of Millennium Development Goals 4, 5 and 6 in Nigeria
}

\author{
Prosper Adogu ${ }^{*}$, Ifeoma Udigwe ${ }^{1}$, Gerald Udigwe ${ }^{2}$, Chika Ubajaka1 \\ ${ }^{1}$ Department of Community Medicine and PHC, NAU/NAUTH, Nnewi, Nigeria \\ ${ }^{2}$ Department of Obstetrics and Gynecology, NAU/NAUTH, Nnewi, Nigeria \\ Email: "prosuperhealth@yahoo.com, princessnewlife@yahoo.com, geraldudigwe@yahoo.com, \\ chika@grunzlink.com
}

Received 9 June 2014; revised 8 July 2014; accepted 7 August 2014

Copyright () 2014 by authors and Scientific Research Publishing Inc.

This work is licensed under the Creative Commons Attribution International License (CC BY).

http://creativecommons.org/licenses/by/4.0/

(c) $\underset{\mathrm{EY}}{\mathrm{i}}$ Open Access

\begin{abstract}
Introduction: The problems of adolescents' sexual behavior are grave and far-reaching. Methods: Review of exiting literature via Google scholar, AJOL, Pubmed, HINARI and other relevant data bases on the common problems of adolescents' inappropriate sexual behavior. Result: Adolescent sexual behavior could result in adolescent pregnancy which prevalence varies widely throughout Nigeria perhaps due to differences in culture and development. Abortion, the willful termination of pregnancy is another problem which is often undertaken for pregnancies resulting from incest and sexual abuse. Also common is trans-generational sex which occurs when an adolescent has non-marital sex in the last $\mathbf{1 2}$ months with a man who is at least 10 years older than her. Also related to this, is transactional sex found in both committed and casual relationships. It is not always done for survival because in some cultures, sex for favor is carried out for reasons other than subsistence. Furthermore, multiple sexual partners are the engagement in sex with more than one partner over a particular time frame. It may be sequential or concurrent. The high prevalence of these problems in Nigeria raises a question of the possibility of achieving the millennium development goals (MDGs) 4, 5 and 6 specifically targeted at reducing child mortality, improving maternal health and combating HIV/AIDS, malaria and other diseases respectively. Conclusion: Policies and strategies such as family life and HIV/AIDs education (FLHE) curriculum on adolescent reproductive health should be pursued with greater vigor in our secondary schools in addition to establishing HIV counseling centers and vocational training programs for out-of-school adolescents. WHO support and commitment to key action areas for countries and member states will build and strengthen their capacity to improve reproductive and sexual health.
\end{abstract}

\footnotetext{
${ }^{*}$ Corresponding author.
} 


\section{Keywords}

\section{Adolescent, Sexual Behavior, Millennium Development Goals 4, 5, 6, Nigeria}

\section{Introduction}

Reproductive health is a state of complete physical, mental and social well-being and not merely the absence of disease or infirmity, in all matters related to the reproductive system and to its functions and process. It includes sexual health, the purpose of which is the enhancement of life and personal relations, and not merely counseling and care related to reproduction and sexually transmitted diseases [1]. It has many components and many of which reflects health status in the adolescents' sexual and reproductive lives. Some of the components which involve adolescents include: promotion of healthy sexual maturation as from pre-adolescence, prevention and management of reproductive tract infections, prevention and management of complications of abortion, provision of safe abortion where the law permits, gender equality and elimination of harmful practices. In Nigeria, young people (10 - 24 years) constitute one-third of the country's total population [2]. Ignoring the reproductive and sexual health of this group will have dire national consequences for decades. Investing in them will provide a healthy labor force and strengthen the economy for years. The consequences of unsafe sex including HIV infections are suffered mostly by young women [3] [4]. It is estimated that each case of AIDS in a country results in additional annual medical care costs that is equal to 2.7 times the level of the country's per capital gross national product (GNP) [3]. The MDGs 4, 5 and 6 will be achieved by any government that tackles young people's reproductive and sexual health needs and problems [1] [5]. All of these will have positive impact both on the nations' economy and generations of young people, their families and communities.

Anambra state, Nigeria has been identified as having adolescents with poor sexual health indices [6]. This review describes some problems of adolescent sexual behavior, possible causes and consequences among adolescents in the state. Some of the problems identified include: adolescent pregnancy, abortion, trans-generational sex, transactional sex and multiple sexual partners. The study briefly examines the role of millennium development goals (MDGs) relevant to adolescent reproductive and sexual health, and proffers solutions from the standpoint of national and international policies and strategies.

\section{Main Body of Text}

\subsection{Adolescent Pregnancy}

Unintended pregnancy among adolescents is a common public health problem worldwide. About 16 million women 15 - 19 years old give birth each year, contributing to $11 \%$ of all births worldwide [1]. Seventy percent of all adolescents' birth takes place in Sub-Saharan Africa [1]. In Nigeria, by the age of 19 years, 23\% of adolescents must have given birth to a child [6]. The prevalence is higher in most studies carried out in Nigeria; as depicted by studies carried out among female adolescents in Port Harcourt which reported 78.8\% prevalence [7], Owerri which gave a prevalence of $31.6 \%$ with $78.9 \%$ pregnancy recurrence [8]. Conversely, a study in the Northcentral part of Nigeria reported a much lower adolescent pregnancy prevalence of only 5.1\%. [9]. The variation in prevalence could be due to different cultures and industrialization in different parts of the country. For instance, people in the North-central part of Nigeria believe in early marriage for their teens and therefore the incidence of teenage pregnancy is expectedly low in such places.

Unplanned pregnancies (including teenage pregnancies) are the result of various factors such as poverty, early sexual debut, a lack of knowledge about menstruation and pregnancy, a lack of access to, and knowledge about how to use contraceptives, difficulties in using contraceptives because of a partner's or family's objections; contraceptive failure, and sexual assault [10]. A study carried out among adolescents in Congo, identified factors such as unemployed mothers, early puberty, absence of sex education and being out-of-school; as major risk factors to adolescent pregnancy rates [11]. Other important factors increasing the prevalence of unintended pregnancy among adolescents are early sexual debut and coerced sex. In most studies, including NDHS 2008, early sexual debut and coerced sex are more prevalent in those with low educational status, and is associated with increasing level of teenage pregnancy among out-of-school adolescents compared to those in school. Coerced sex, 
reported by $10 \%$ of girls who first had sex before the age of 15 years contributes to unwanted adolescent pregnancies [1].

Adolescent childbearing poses health risks for both mother and child. Some of the risks include toxemia, hemorrhage, anemia, infection especially HIV, malnutrition, cephalo-pelvic-disproportion, obstructed labour, vesico-vaginal fistula, low birth weight and perinatal and maternal mortality. Thirty-sixty percent end up in abortion with its sequelae [12]. The social and economic consequences of adolescent pregnancy and childbearing depend on the adolescent's particular cultural, family and community settings. In many African countries like Nigeria, adolescents' pregnancy is associated with poor educational achievement, poverty, limited employment opportunities, dependency on social welfare and rejection by family members' discrimination, psycho-social stress, forced marriage and violence [13]. Most studies conducted amongst adolescents reported that termination of schooling is associated with unintended pregnancy among students. A recent study in Nigeria reported that 43\% discontinued schooling [12] and in Congo, up to $82.4 \%$ of adolescents gave up schooling [11].

Adolescent mothers may pass on to their children, a legacy of poor health, substandard education and subsistence living, creating a cycle of poverty that is hard to break [13]. Several studies have shown that some victims of unintended pregnancy were more likely to be children of mothers with limited school education and history of unintended teenage pregnancies. Most adolescents are aware that promiscuous sexual activity puts them at risk of getting pregnant or contacting HIV, though their knowledge, often laced with myths, is devoid of scientific depth. For example, many adolescents think that a young woman cannot get pregnant at the first time she has sexual contact or if she has sex standing up [14]. Teenage pregnancy is a risk factor for disruption of education, future unemployment, STI, HIV, preterm birth and poor mental health and is a reflection of inconsistent use of contraception [15].

\subsection{Abortion}

The World Health Organization defines unsafe abortion as a procedure for terminating an unintended pregnancy carried out either by persons lacking the necessary skills or in an environment that does not conform to minimal medical standards or both. Worldwide, $48 \%$ of all induced abortions are unsafe [16]. In developed countries $92 \%$ are safe while $55 \%$ are unsafe in developing countries. Adolescents 15 - 19 years old contribute to $25 \%$ of abortions in Africa [17]. In Nigeria, 60\% of all abortions are attributed to adolescents [2]. A recent study carried out in Nigeria reported as much as $100 \%$ prevalence of those who were ever pregnant [18], while another study reported a lower prevalence of $20.2 \%$ [19].

The reasons why adolescents terminate pregnancies include; pregnancy from incest or sexual abuse, contraceptive failure, fears of upsetting parents or bringing shame to the family, fears of expulsion from the family home, school or jobs, fears of difficulty in finding a marriage partner, lack of financial means to care for a child, desire to complete education or achieve other goals, dislike for the man who caused the pregnancy [20]. Abortion in Nigeria is highly restricted by law; the procedure is often performed clandestinely and under unsafe conditions. Such procedures pose serious health and social risks. A study done in Nigeria estimates that $50 \%$ of the Nigerian women who die from unsafe abortion each year are adolescents, and abortion complications are responsible for $72 \%$ of all deaths among teenagers below the age of 19 years [20].

Risk of complications of abortion is usually higher in adolescents than in other women because, they may postpone having abortion until after the first trimester because they do not recognize or acknowledge the pregnancy, they fear the abortion procedure or parental reaction or they need time to find money to pay for the procedure [21].

Complications due to unsafe abortion account for $13 \%$ of maternal deaths worldwide [16]. Other consequences of unsafe abortion include loss of productivity, economic burden on public health system, stigma and long-term health problems such as infertility. Some of the medical consequences include; cervical or vaginal laceration, sepsis, hemorrhage, bowel or uterine perforation, tetanus, pelvic infections or abscesses, chronic pelvic inflammatory disease and secondary infertility. Compared to adults, adolescents are more likely to delay abortion, resort to unskilled persons to perform it, use dangerous methods and present late when complication arise.

\subsection{Trans-Generational Sex}

Trans-generational sex or age mixing is defined as "Woman aged 15 - 19 who have had non-marital sex in the last 12 months with a man who is 10 years or more older than themselves" The current prevalence of Trans- 
generational sex among Nigerian young women is 11\%, 6 in Ghana 38\% [22], in South-Africa the prevalence is 33\% [23]. A study in Port Harcourt Nigeria reported a very high prevalence of 74.2\% [7]. This is not surprising as many wealthy men are residing in the oil rich city; these men deceive young girls into having sex with them in exchange for money and other material benefits.

Adolescent girls in Sub-Saharan African are highly vulnerable to engaging in trans-generational sex for reasons which include; exchanging sex for cash or material things due to widespread poverty [24]. Older men preferring younger adolescent partners, who are perceived to be free from HIV infection and the decline of traditional societal structures which has led to decrease in family control over the behaviour of young people as well as a gap in young women's knowledge of sex. Research has shown that girls appear vulnerable to cross-generational sex due to their poverty. And when it is not poverty, they are drawn to the transactional nature of it, receiving gifts, money, and cell phone in exchange for sex. Other reasons or factors influencing such relationship include; improving one's social status, pleasure, love, material comfort, security, life maintenance, school fees, booths, uniform, food, housing, insecurity, fear of physical or other harms [25]. Many programs and intervention have been put in place to reduce this menace in Sub-Saharan Africa but none yet has been evaluated for its effectiveness [24].

Young women in sexual relationships with older partners have been found to have poor reproductive health outcomes, including increased risk for HIV infection and sexually transmitted infection [24] [26] [27]. The risks associated with cross-generational sex may be in part due to the power imbalances between the partners [26] [27]. Particularly if a young woman is dependent on an older man for financial support, she may have little power to negotiate safe sex. Some studies carried out on adolescents in Sub-Saharan Africa have shown that cross-generational sex often involves sex in exchange for money or goods, characterized by less condom use and greater sexual coercion [26]-[28]. Although, most cross-generational sex is transactional, it is differentiated from commercial sex or prostitution. Girls involved in prostitution or commercial sex are easily located in a place or building and get involved with many sex partners of different age groups. This is confirmed from a review of some studies in Sub-Saharan Africa where there was a transactional component to sexual relations for adolescent girls who were not engaged in trafficking and prostitution [26].

A US study, using a sample of adolescents, found that women who initiated sex with older partner were significantly more likely to have been pregnant during their lifetime and less likely to use condoms at first sex, last sex and during their lifetime [26]. The power imbalances in such relationships may lead to lack of communication between partners, thus limiting a young woman's ability to advocate for Condom and contraceptive use. A study carried out in Zimbabwe revealed that the substantial age differences between female and male sexual partners was identified as the major behavioral determinant of the more rapid rise in HIV prevalence in young women than in men [26].

\subsection{Transactional Sex}

Transactional sex is the offering of sex for money or favour. Although the practice is worldwide, it is thought to be more prevalent in sub-Saharan Africa. People who practice transactional sex live in the general population and may have primary means of sustenance or engagement such as schooling or job [29]. Transactional sex has been noted to be one of the factors fuelling the HIV epidemic. Transactional sex is so common that it is found in both casual and committed relationships. In a study in Ghana, $84 \%$ of prevalent cases of HIV were attributable to transactional sex [30]. A study carried out among young women in South-eastern part of Nigeria reported that as many as $93 \%$ of the respondents had sexual relationships due to financial gains [31].

It has been found to be very common among sexually active unmarried female adolescents. A study done in four countries of Ghana, Burkina-Faso, Malawi and Uganda using national survey, in-depth interviews and focus group discussions found that money (93\%), clothes (33\% - 63\%) and jewellery and cosmetics are the most commonly exchanged items [32]. This scenario cuts across ages, in school and out of school girls. Socioeconomic factors including poverty lead many young girls to use premarital sexual relations for economic support [29] [33]. However this tends to weaken their bargaining power in relation to safe sexual behaviour including use of condoms and rendered them more vulnerable [34]. The outcome especially in young uneducated or street girls is a sequence of events such as pregnancy, unsafe abortion and sexually transmitted infection including HIV.

In most societies, exchange of sex for favor or gifts is taken as normal. In most cases the gifts flow from the 
male to the female gender and although it is usually more obvious in trans-generational sex, it equally occurs among age mates such as school mates. Transactional sex is not always for survival. In some cultures, societies or settings, sex for favour or gifts is carried out for other reasons other than subsistence. In a study from the University of Zimbabwe, girls engage in sex for favour or gift to be able to compete for social status in their peer groups as well as to fashion themselves as high status modern subjects [35].

\subsection{Multiple Sexual Partners}

Multiple sexual partners entail the engagement in sex with more than one partner over a particular time frame. It may be sequential (serial monogamy) or concurrent. A notable number of adolescents are engaged in sexual activity and a few use condoms during sex even those with multiple partners probably due to limited knowledge on safe sex, cultural norms, unfriendly environment for condom accessibility and thus exposing themselves to risk of contracting STIs including HIV and unwanted pregnancies. The prevalence is usually high among adolescents. Several studies in Nigeria and other parts of Africa reported a high prevalence of adolescents who had multiple sexual partners [36]-[40]. In Congo, the prevalence is 51\%, [34] Benin 35\%, [37] Lagos 58\%, [36] and Owerri 53.2\% [41]. However, the prevalence is often higher among the out-of-school adolescents compared to in-school adolescents. A comparative study of the two groups in Uganda reported that $13 \%$ of those in-schools had multiple sexual partners compared to $22 \%$ of the out-of-school adolescents.

People engage multiple sexual partners for different reasons. In a study done in Tanzania using in-depth interviews and focus group discussions in young men and women aged 16 to 24 years, it was found that pursuit of multiple sexual partners for boys is sexually motivated while girls are involved for economic reasons [34]. A closer look will reveal proximate factors for multiple sexual partnerships. The uses of alcohol and illicit drugs as well as young age at first coitus are factors that contribute to pursuit of multiple sexual partnerships [32] [34] [42]. In another study in the United States among 14 - 22 years old, these factors were associated with increased odds that females had two or more partners in the preceding three months [43] [44]. In Uganda and South Africa, the pursuit of multiple sexual partners is underpinned by exchange of gifts or favors and this affects the ability to negotiate the terms of sexual relationship [32].

The more desperate a need is, the weaker the power to negotiate. The consequences are many fold especially following unprotected sexual intercourse. These include pregnancy, unsafe abortion, dropping out of school, sexually transmitted infections including HIV. There is also a cascade mechanism with regard to the spread of STIs among people that have multiple sexual partners. People with multiple sexual partners tend to choose consorts with multiple sexual partners so that each person is exposed in a geometric fashion to the possibility of acquiring STIs. The practice of multiple sexual partners is not always for subsistence. In some societies, it is cultural and in other it boosts the ego of the men folk. In South Africa, women exploit multiple sexual relationships in the interest of new "needs" the commodities of modernity [45]. In Uganda multiple sexual partnerships are highly valued as sign of sophistication. Some keep multiple sexual partners so that they can choose one for marriage or gain experience which they consider vital in marriage [32].

\subsection{Millennium Development Goals and Adolescents' Reproductive and Sexual Health}

The Millennium Development Goals which grew out of the United Nations Millennium Declaration adopted by 189 member states in 2000 provide the framework for measuring progress towards sustaining development and eliminating poverty [1].

Three $(4,5$ and 6$)$ out of the eight goals are directly related to reproductive and sexual health while others have a close relationship with reproductive health.

\subsubsection{Goal 4: Reduce Child Mortality}

The major causes of child mortality in developing countries are lack of utilization of family planning, malnutrition, diarrhea, malaria, respiratory tract infections, lack of sexual and reproductive health education and services, and poverty. Improving the health of the mother is the first step to reducing child mortality. The chances of child survival increase when the mother has more education, not only because she is older but because she has learned more about hygiene, nutrition and can read and understand the material that accompanies any medicine she receives. Early marriage and adolescent pregnancy can severely threaten child survival. Studies have shown rates of newborn death to average $50 \%$ higher to adolescent mothers compared to mothers in their 20s [1]. A combination of physical and socioeconomic factors place babies of youngest mothers at risk of dying. A study 
carried out in America found a 55\% higher risk of neonatal death to babies of mothers aged 10 - 15, a 19\% higher risk in babies of $16-17$ years old and a 6\% risk in babies of 18 - 19 years old [46]. The adverse impact of poor newborn health due to adolescent pregnancies can have inter-generational effects and also long term effects leading to adulthood disease. Prenatal care and ability to avoid high risks births especially among young women help prevent infant and child deaths.

\subsubsection{Goal 5: Improve Maternal Health}

Unprotected sex puts young people especially the females at risk of unwanted pregnancy, which may contribute to marrying early, abandoning babies, obtaining unsafe abortions or contracting HIV and other sexually transmitted diseases. These and many more endanger the health of the young woman or adolescent. WHO estimated that young people contribute $11 \%$ of all births worldwide, $95 \%$ occur in developing countries and majority occur in seven countries of which Nigeria is included [1]. In Nigeria, 23\% of young women have begun child bearing and $60 \%$ of abortions is attributed to them. Unsafe abortion contributes $13 \%$ of all maternal deaths and the risk of maternal death at childbirth is greater as maternal age decreases, with adolescents under 16 years facing four times the risk of maternal death as women over 20 [46]. Conditions associating adolescent childbearing and maternal health problems include obesity, anemia, mental illness, unsafe abortion complications, STIs and obstetric fistula [1]. Adolescent mothers often lack knowledge, education, experience, income, and power relative to older mothers. Thus, they need a continuum of care that starts in the household and community and extends into the healthcare system, including care for complications.

\subsubsection{Goal 6: Combating HIV/AIDs, Malaria and Other Diseases}

More than two-thirds of new HIV infections are in sub-Saharan Africa. WHO is working with countries: to prevent people becoming infected with HIV—helping to change behaviours to reduce HIV risks; increasing access to prevention commodities; supporting programmes for prevention of mother to child transmission of HIV; promoting safe blood supplies and prevention of HIV transmission in health care settings; assessing new prevention technologies; to expand the availability of treatment; to provide the best care for people living with HIV/ AIDS and their families; to expand access and uptake of HIV testing and counseling so that people can learn their HIV status; to strengthen health care systems so that they can deliver quality and sustainable HIV/AIDS programmes and services; and to improve HIV/AIDS information systems, including HIV surveillance, monitoring and evaluation and operational research [47].

Despite the above laudable objectives of MDG 6, it is sadly known that the greatest known risky sexual practices associated with increased HIV prevalence still remains unprotected sex, multiple sexual partners and young age at first sex (prevalent among the youths). Young people aged 10 - 24 years account for half of all new HIV infections worldwide [48]. The growth of the epidemic in this age group is related, among other causes to increase in risk-taking activities, to social stigma associated to HIV infection, to the lack of access to preventive sexual and reproductive health services, to difficulties in obtaining information (both in-school and out-ofschool), to insufficient health policies designed to the needs of the youth. Young women are highly vulnerable to the infection in developing countries more than the young men. They make up approximately two-thirds of those under 25 years with HIV worldwide and it is estimated that globally, young women are 1.6 times more likely to be living with HIV/AIDS than young men [48]. The higher vulnerability of young women to HIV are associated with gender discrimination, economic deprivation, deficiency in educational systems, lack of power to negotiate sexual relationships, high incidence of violence and rape. They are also more vulnerable than older women because their reproductive tract contain fewer layers of epithelial cells, which offer less protective barrier against viral infections, than multiple layers of epithelial squamous cells found in the vaginas of adult women [48]. Despite the fact that majority of young people have heard of AIDS, many still do not know how to prevent transmission, and misconceptions abound about HIV/AIDS. NDHS 2008 reported that only $17 \%$ of our youth had comprehensive knowledge of HIV [6]. Young people therefore need increased access to information about sexuality and reproduction, youth-friendly services, encouragement in consistent use of condoms, mass media interventions and many diverse programs. They should be involved in the planning, implementation and evaluation of their programs.

\section{Conclusions and Recommendations}

The avalanche of problems and consequences of adolescent sexual behavior as identified in this brief review in- 
clud but not are limited to adolescent pregnancy, abortion, trans-generational sex, transactional sex and multiple sexual partners. They leave a herculean challenge for government and other stakeholders to find solutions to them. Therefore, international, national and local non-governmental organizations that have been already implementing programs to promote the reproductive health of the youth in the state should redouble their efforts with a view to making them more effective. These programs should be reviewed to also ensure accessibility to all adolescents.

WHO proposes the following five key action areas for countries, and is committed to supporting member states in building and strengthening their capacity to improve reproductive and sexual health [1]: Strengthening health systems capacity, improving information for priority setting, mobilizing political will, creating supportive legislative and regulating frame works, strengthening, monitoring, evaluation and accountability. These strategies must be pursued with greater vigor because they form the bedrock for actualization of the national adolescent reproductive and sexual strategy.

In 1999, the Nigerian government formulated a national adolescent reproductive health strategic framework which was revised in 2008. The revised framework was provided through partnership with various federal ministries, government agencies and non-governmental organizations, as well as input from the WHO and young people themselves. This includes: Family life and HIV/AIDs education (FLHE) curriculum as part of an attempt to improve sex education in schools, FHLE over internet and phones aimed at youth access to computer and mobile phones, Youth - friendly health services, including HIV counseling centers and vocational training programmes, as well as centers for adolescents that build communication and provide channels for information dissemination.

\section{References}

[1] World Health Organization (2004) Reproductive Health Strategy. WHO, Geneva.

[2] Federal Ministry of Health (2009) Assessment Report of the National Responses to Young People's Sexual and Reproductive Health in Nigeria.

[3] Biddle, A., Hessburg, L., Singh, S., Bankole, A. and Darubi, L. (2007) Protecting the Next Generation in Sub-Saharan Africa. Alan Guttermacher Institute.

[4] Alan Guttermacher Institute (2006) Risk and Protection: Youth and HIV/AIDS in Sub-Saharan Africa. Alan Guttermacher Institute, New York.

[5] Population Reference Bureau (2006) The World Youth 2006 Data Sheet. (Accessed 22/04/10). http://www.prb.org/publications/Datasheets/2006/...aspx

[6] National Population Commission (NPC) and ICF Macro (2009) Nigeria Demographic and Health Survey 2008. National Population Commission and ICF Macro, Abuja, Nigeria.

[7] Okpani, A.O. and Okpani, J.U. (2000) Sexual Activity and Contraceptive Use among Female Adolescents-Report from Port Harcourt, Nigeria. African Journal of Reproductive Health, 4, 40-47. http://dx.doi.org/10.2307/3583241

[8] Okereke, C.I. (2010) Unmet Reproductive Health Needs. Health Seeking Behavior of Adolescents in Owerri, Nigeria. African Journal of Reproductive Health, 14, 43-54.

[9] Adekunle, L.A., Ricketts, O.Z., Ajunwon, A.J. and Ladipo, O.A. (2009) Sexual and Reproductive Health Knowledge, Behavior and Education Needs of In-School Adolescents in Northern Nigeria. African Journal of Reproductive Health, 13, 37-39.

[10] Bryan, D. and Packer, M.S. (2004) Adolescents, Unwanted Pregnancy and Abortion. Ipas, Chapel Hill.

[11] Mabiala, J.R., Massamba, A., Bantsima, T. and Senga, P. (2008) Sexual Behaviour among Adolescent in Brazzaville, Congo. Journal de Gynécologie Obstétrique et Biologie de la Reproduction, 37, 510-515.

[12] Onyeka, I.N., Miettola J., Ilika, A.L. and Vaskilampi, T. (2011) Unintended Pregnancy and Termination of Studies among Students in Anambra State, Nigeria. African Journal of Reproductive Health, 15, 109.

[13] World Health Organization (2008) Adolescent Pregnant-Unmet Needs Undone Deeds. WHO, Geneva.

[14] Elfebein, D.S. and Felice, M.E. (2003) Adolescent Pregnancy. Pediatric Clinics of North America, 50, 781-800. http://dx.doi.org/10.1016/S0031-3955(03)00069-5

[15] Guttmacher Policy Review (2007) Young People Need Help in Preventing Pregnancy and HIV, How Will the World Respond? GMI.

[16] Alan Guttmacher Institute (2011) Facts on Induced Abortion Worldwide in Brief. Fact Sheet, Alan Guttermacher Institute. 
[17] Odu, O.O., Asekun, E.O., Bamidele, J.O., Egbewale, B.E., Amusan, O.A. and Olowu, A.O. (2008) Knowledge, Attitudes to HIV/AIDS and Sexual Behavior of Students in a Tertiary Institution in South-Western Nigeria.

[18] Aderibigbe, S.A. and Araoye, M.O. (2008) Effect of Health Education on Sexual Behavior of Students of Public Secondary Schools in Llorin, Nigeria. European Journal of Public Health, 24, 33-41

[19] Okereke, C.I. (2010) Unmet Reproductive Health Needs. Health Seeking Behavior of Adolescents in Owerri, Nigeria. African Journal of Reproductive Health, 14, 43-54.

[20] Grimes, D.A., Benson, J., Singh, S., Romero, M., Ganatra, B., Okonofua, F.E., et al. (2006) Unsafe Abortion: The Preventable Pandemic. The Lancet, 368, 1908-1919. http://dx.doi.org/10.1016/S0140-6736(06)69481-6

[21] Raufu, A. (2002) Unsafe Abortion Cause 20,000 Deaths a Year in Nigeria. BMJ, 325, 988. http://dx.doi.org/10.1136/bmj.325.7371.988/d

[22] Alan Guttmacher Institute (2006) Adolescents in Ghana New York. Facts in Brie, Alan Guttermacher Institute.

[23] Moore, A.M., Biddlecom, A.E. and Zulu, E.M. (2007) Prevalence and Meanings of Exchange of Money or Gifts for Sex in Unwanted Adolescent Sexual Relationships in Sub-Saharan Africa. African Journal of Reproductive Health, 11, 44-61. http://dx.doi.org/10.2307/25549731

[24] USAID (2003) Cross-Generational Sex: Risks and Opportunities. Briefs. USAID.

[25] Luke, N. (2003) Age and Economic Asymmetries in Sexual Relationships of Adolescents Girls on Sub-Saharan Africa. Studies in Family Planning, 34, 67-86. http://dx.doi.org/10.1111/j.1728-4465.2003.00067.x

[26] Luke, N. and Kurz, K.M. (2002) Cross-Generational and Transactional Sexual Relations in Sub-Saharan Africa. Pop Services International, Washington DC.

[27] Kelly, R.J., Gray, R.H., Sewankambo, N.K., Serwadda, D., Wabwire-Mangen, F., Lutalo, T., et al. (2003) Age Differences in Sexual Partners and Risk of HIV-1 Infections in Rural Uganda. JAIDS Journal of Acquired Immune Deficiency Syndromes, 32, 446-457. http://dx.doi.org/10.1097/00126334-200304010-00016

[28] Gregson, S., Nyamukapa, C.A., Garnett, G.P., Mason, P.R., Zhuwau, T., Caraël, M., et al. (2002) Sexual Mixing Patterns and Sex-Differentials in Teenage Exposure to HIV Infection in Rural Zimbabwe. The Lancet, 359, 1896-1903.

[29] Kanku, T. and Mash, R. (2010) Attitude, Perception and Understanding amongst Teenagers Regarding Teenage Pregnancy Sexuality and Contraception in Tuang South Africa. Form Preact, 52, 563-572

[30] Côté, A., Sobela, F., Dzolcoto, A., Nzambi, K., Asamoah-Adu, C., Labbé, A.C., et al. (2004) Transactional Sex Is the Driving Face in the Dynamics of HIV in Accra, Ghana. AIDS, 18, 917-925. http://dx.doi.org/10.1097/00002030-200404090-00009

[31] Ilika, A. and Igwegbe, A. (2004) Unintended Pregnancy among Unmarried Adolescents and Young Women in Anambra State, South East Nigeria. African Journal of Reproductive Health, 8, 92-102. http://dx.doi.org/10.2307/3583396

[32] Moore, A., Biddlecom, A. and Zulu, E. (2007) Prevalence and Meanings of Exchange of Money or Gifts for Sex in Unmarried Adolescent Sexual Relationships in Sub-Saharan Africa. African Journal of Reproductive Health, 11, 1-19.

[33] Meelar, S.D. and Calves, A. (1997) Man Girl Friends, Girl Friends, Marriage and Money: The Society Context of HIV Risk Behavior in Sub-Saharan Africa. Health Transition Review, 7.

[34] Luke, N. (2003) Age and Economic Asymmetries in the Sexual Relationships of Adolescent Girls in Sub-Saharan Africa. Studies in Family Planning, 34, 67-86. http://dx.doi.org/10.1111/j.1728-4465.2003.00067.x

[35] Masvawure, T. (2010) "I Just Need to Be Freshly on Campus": Female Students and Transactional Sex at a University in Zimbabwe. Culture, Health and Sexuality, 12, 857-870. http://dx.doi.org/10.1080/13691050903471441

[36] Durojaiye, O.C. (2011) Knowledge, Attitude and Practice of HIV/AIDS. Behavioral Change among Tertiary Education Students in Lagos, Nigeria. Annals of Tropical Medicine \& Public Health, 4, 18-24.

[37] Unuigbe, I.E. and Ogbeide, O. (1999) Sexual Behavior and Perception of AIDS among Adolescents in Benin City, Nigeria. African Journal of Reproductive Health, 3, 39-44. http://dx.doi.org/10.2307/3583227

[38] Morhason-Bello, I.O., Oladokan, A., Enakpene, C.A., Fabanwo, A.O., Obisekan, K.A. and Ojengbede, O.A. (2008) Sexual Behavior of In-School Adolescents in Ibadan, South-West Nigeria. African Journal of Reproductive Health, 12, 89-97.

[39] Owoaje, E.T. and Uchendu, O.C. (2009) Sexual Risk Behavior of Street Youth in South-West Nigeria. East African Journal of Public Health, 6, 274-279.

[40] Dare, O.O., Oladepo, O., Cleland, J.G. and Badru, O.B. (2001) Reproductive Health Needs of Young Persons in Markets and Motor Parks in South-West Nigeria. African Journal of Medicine and Medical Sciences, 30, 199-205

[41] Federal Ministry of Health (2006) National HIV/AIDS and Reproductive Health Survey 2005. Federal Ministry of Health, Abuja, Nigeria.

[42] Santelli, J.S., Brener, N.D., Cowry, R. BhaH A. and Zabin, L.S. (1998) Multiple Sexual Partners among U.S. Adoles- 
cents and Young Adults. Family Planning Perspectives, 30, 271-275. http://dx.doi.org/10.2307/2991502

[43] Bamidele, J.O., Abodunrin, O.L. and Adebimpe, W.O. (2009) Sexual Behaviour and Risk of HIV/AIDS among Adolescent in Public School in Osogbo, Osun State, Nigeria. International Journal of Adolescent Medicine and Health, 2, 387-394.

[44] National Population Commission (2008) Reports on 2008 Population Census in Nigeria.

[45] Madalla, L.S. (2003) Transactional Sex and the Pursuit of Modernity. Social Dynamics, 29, 213-233.

[46] WHO (2008) Adolescent Pregnancy: Document. WHO, Geneva.

[47] WHO. Millennium Development Goal 6: Combat HIV/AIDS, Malaria and Other Diseases.

[48] UNAIDS (2009) Sub-Saharan AIDS Epidemic. Update. http://data.unaids.org/pub/facts/2009/20091124_FS_SSAen.pdf 
Scientific Research Publishing (SCIRP) is one of the largest Open Access journal publishers. It is currently publishing more than 200 open access, online, peer-reviewed journals covering a wide range of academic disciplines. SCIRP serves the worldwide academic communities and contributes to the progress and application of science with its publication.

Other selected journals from SCIRP are listed as below. Submit your manuscript to us via either submit@scirp.org or Online Submission Portal.
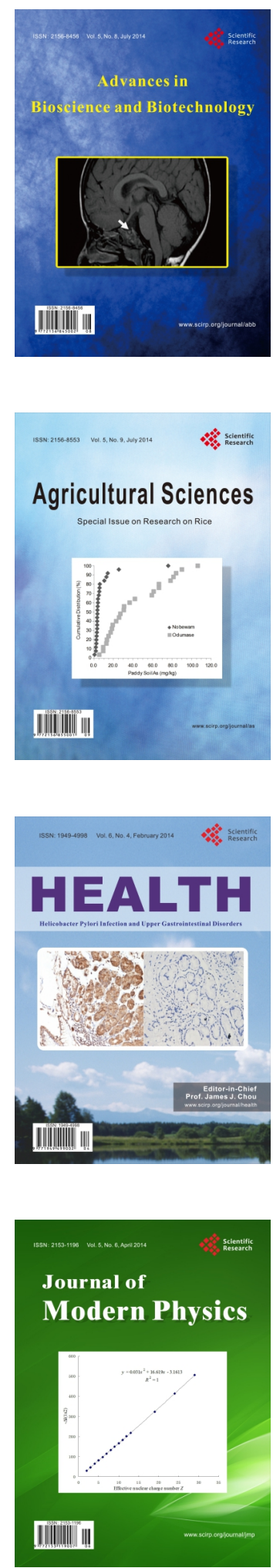
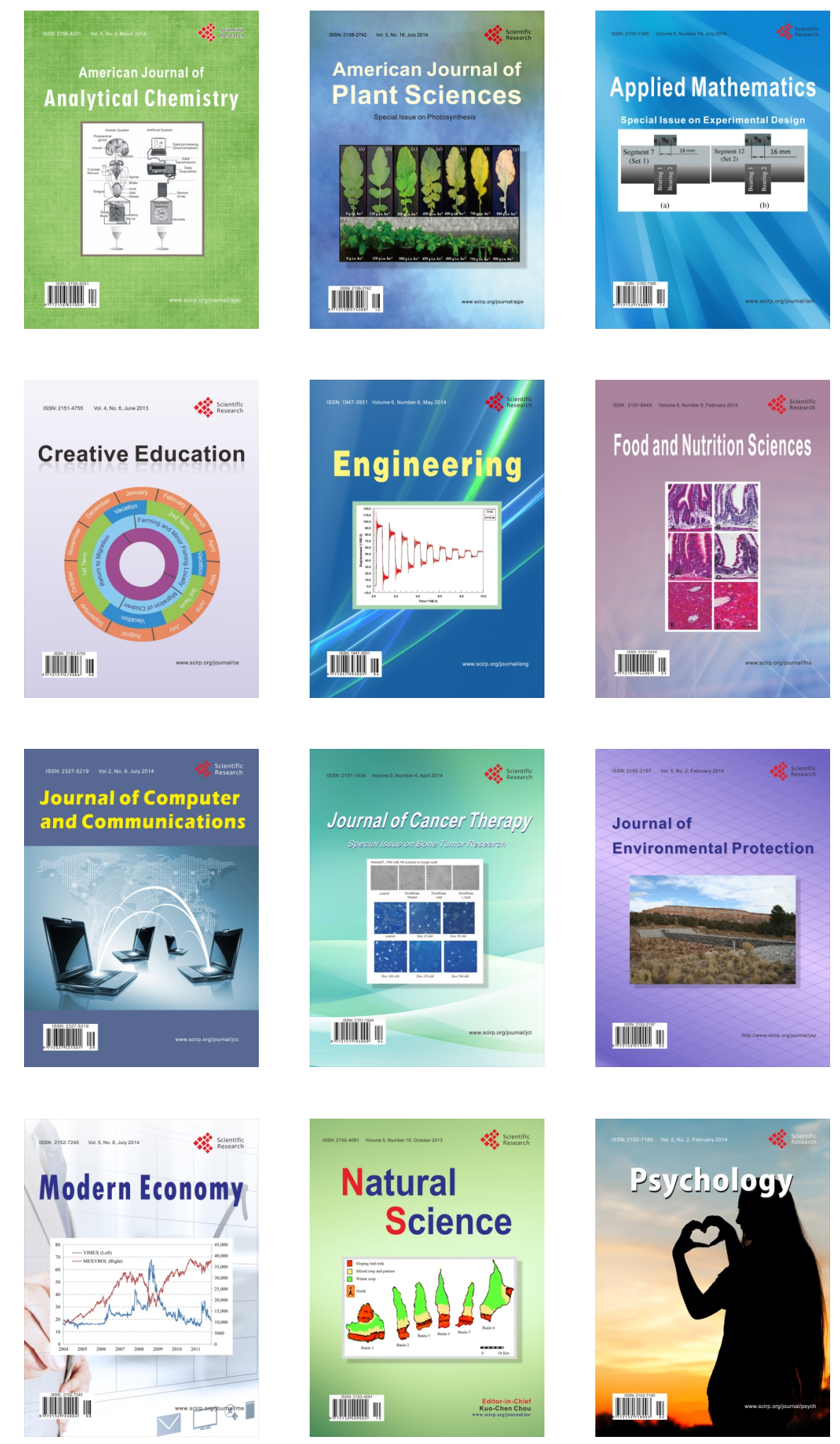